\title{
Impact Analysis of Integrated Watershed Management Program on Farmers' Income in a Hilly Tribal Area of India
}

\author{
K.M. Gojiya ${ }^{1 *}$, C.S. Matholiya ${ }^{2}$ and S.K. Gaadhe ${ }^{2}$ \\ ${ }^{1}$ Department of Soil and Water Conservation Engineering, ${ }^{2}$ Department of Farm Machinery \\ and Power Engineering, College of Agricultural Engineering and Technology, Junagadh \\ Agricultural University, Gujarat, 362001, India, India \\ *Corresponding author
}

\section{A B S T R A C T}

\begin{tabular}{|l|}
\hline Ke y w o r d s \\
Integrated \\
watershed, \\
Management \\
program, \\
Income, \\
Tribal area \\
\hline Article Info \\
\hline $\begin{array}{l}\text { Accepted: } \\
\text { 17 November } 2018 \\
\text { Available Online: } \\
\text { 10 December } 2018\end{array}$ \\
\hline
\end{tabular}

\section{Introduction}

Fresh water assets are winding up rare with the expanding request of the developing populace. Comprehensively, 783 million individuals don't approach clean drinking water and relatively 2.5 billion don't approach satisfactory sanitation and this affects their prosperity. In India, 144 million individuals need access to clean drinking water (Fledderjohann et al., 2015). Water shortage joined with lacking cleanliness and sanitation has a monstrous wellbeing impact, especially
In the study it was observed that from 9 structures in IWMP-2 project at different villages of Madhya Pradesh, during Rabi, about 146 farmers were benefited. The farmers reported that in total about 16 percent area of cultivation increased especially in winter and summer and they received very good increase in overall production about 38 percent. Study revealed that due to structures, farmers were able to cultivate more gaining crops as irrigation water availability was increased. Moreover, benefit cost analysis showed that all the construction cost of structures was recovered in 3 to 4 years and continued to benefit the beneficiary tribal farmers. We also observed that small farmers have come to get about above 50 percent overall benefits on average and medium farmers are getting lower about $10-25$ percent of benefits from the different structures in IWMP-2 project.

from diarrheal maladies. In rural areas, where employment is exceptionally subjected to agriculture, water is required for profitable purposes, for example, farming exercises in addition to domestic necessities (Nerkar et al., 2016). In India, indigenous individuals who live in geologically secluded living spaces, for example, forest and hilly regions, and have distinctive cultures, are perceived as tribes. The tribal populace in India is around 104 million and $90 \%$ of them live in rural regions (Chandramauli, 2011). Tribal people typically live in the hilly areas in India. The 
employment of these inborn individuals is subject to rain-sustained agriculture which regularly experiences water shortage.

In undulated land areas where lifeline agriculture is already very challenging, the shortage of water worsens the condition. The issues of water shortage in such regions can be tackled via expanding water accessibility and water profitability by implementation of integrated watershed management programmes (IWMP). Integrated watershed management is a procedure of detailing and incorporating a course of action including human resources and natural resources in a watershed, considering the social, political, financial and institutional factors working inside the watershed and encompassing river basin and other important regions, to accomplish explicit social targets (Dixon and Easter, 1986). It is the coordinated management of land, water and biomass assets inside a watershed. An IWMP with community participation and aggregate activity is profoundly powerful in terms of improved economic, social and ecological increases. Anideal IWMP emphases around soil and water protection as well as on exercises like enhancement in agriculture, tree plantation, enhancing cleanliness and sanitation, development of self-help groups (SHGs) and drinking water management (Nerkar et al., 2016). In India, IWMP programs vary among the watersheds from four to seven years in general. An IWMP is supported by the government in India that includes participation of people as well. The watershed project (IWMP) is given to any Project Implementing Agency (PIA) such as $\mathrm{NGO}$, to execute it by the government. PIA has its own project implementing team including team leader, civil engineer, agriculture expert, livelihood expert, social welfare expert, etc. IWMP gives a cluster of villages like rain fed areas, some treatments for 5-7 years and makes the area more productive and irrigated by making soil and water conservation (SWC) structures, some social works, agriculture enhancement and livelihoods. In result this will increase the productivity of the farmers. It also conserves the soil moisture. Soil and water erosions are also reduced.This study focused on the impact of watershed development structures on farmers' incomes and financial recovery period of these structures for a completed IWMP in Madhya Pradesh, India.

\section{Materials and Methods}

\section{Study area}

The watershed management project IWMP-2 implemented by NGO named Development Support Centre (DSC) is located in Mhow city of Indore District which is shown in Figure 1. The project covered a cluster of 9 village farming 4 micro watersheds comprising 5022 ha area.

\section{Watershed development work}

For development of watershed in IWMP-2, Ridge to Valley system, in which work starts from the highest point of watershed and consequently goes down to lower altitudes to the last outlet was executed. In which, for areas having steeper slopes of 8 to 10 percent on very upstream end contour trenches were constructed, in primary gullies loose boulder check dam were constructed, for secondary gullies gabion structures were constructed and for larger gullies, reinforced masonry structure (RMS) or stop dams like permanent structures were built at downstream ends. Moreover, farm bunds for soil conservation in farms, in some sloppy farms for water storage and increase ground water level farm ponds were also made, vegetative measures like grass, shrubs and small tree plantations were also performed to serve an important role in conserving soils. Farmers were also 
encouraged to produce vermicompost to improve soil health and generate extra income.

\section{Impact benefits of structures}

For evaluating the impact benefits of the structures built during IWMP-2, face to face individual conversations with the beneficiary farmers were used for data collection. Impact of total 9 permanent structures was undertaken in the study and to get the data, total 44 local farmers were communicated and data was collected. Details such as production per acre, local prices and cost for sowing of major 8 crops were taken into consideration. When available, details of water rise in wells were also noted. It is important to note that, in the present study only development work of IWMP-2 is studied, agriculture and livelihood activities are not involved which accounts for overall more benefits.

Details of data collected are displayed in Table 1. Beneficiary individuals were asked about their land holdings, irrigation facilities, approximate water-tables, cropping patterns and estimated approximate income of them before and after the structures were built.

Benefit cost analysis of all the structures was done (Newkirk, 1999) using all the collected income information. Benefit-Cost ratio (BCR) was calculated using formula:

$B C R=\frac{\text { Total income from the structure }}{\text { Total cost of structure }}$

It should be noted that general permanent IWMP structures' life is considered to be around six to eight years (Singh et al., 2010) before it gets completely field with sediments. In the present study for uniformity, average life expected was considered to be five years for all the structures. Cost of construction of the structures and other expenditure data were referred from DSC annual report. So, yearly benefits were multiplied for five years to calculate total income in five years. The value of BCR more than one indicates the structure cost was recovered within five years of time and will continue to benefit the populace more.

\section{Results and Discussion}

\section{Development work in IWMP-2}

\section{Vermicomposting}

About 27 vermicompost beds were developed by individual farmers having a production capacity of 150 quintals. The women vermicompost producer group in Badiya village increased the number of vermibeds from 7 to 12 and therefore its production capacity increased by 20 quintals.

The group sold 96 quintal vermicompost in just one year worth ₹ 48000. Hence, the group production of individual and group vermicompost units reached 240 quintals that would save use of area worth ₹ 2.33 lakhs annually.

\section{Seed replacement}

In Rabi 2013-14, about 146 farmers benefited from seed replacement activity when they cropped pusa 111 variety of wheat. The farmers reported that they received very good production increased from 599 quintals to 777 quintals from 28 Hectares land. Similarly in Kharif 2013-14, 100100 quintals seed of JS 335 variety of soybean seed was given to 400 farmers in 80 big ha land.

\section{Women SHGs}

About 100 women SHG members (from 26 SHGs having 268 members) cultivated vegetables on the small patches of land near their house. They saved about ₹ 58,000 from 
using vegetables from their own kitchen garden i.e. also helped in nutrition supplement to their children and family.

\section{Impact benefits of structures}

\section{Structure-1}

Construction cost of structure-1 was ₹ 10.81 lakh. Major five beneficiary farmers were communicated to assess the impacts. Average water rise was about $30 \mathrm{ft}$. Total area of cultivation near the structure was increased from 59 to 68 acre. Total income rise was investigated around 2.4 lakh rupees.

\section{Structure-2}

Construction cost of structure-2 was ₹ 3.31 lakh. Major four beneficiary farmers were communicated to assess the impacts. Average water rise was about $20 \mathrm{ft}$. Total area of cultivation near the structure was increased from 118 to 123 acre. Total income rise was investigated around 2.4 lakh rupees.

\section{Structure-3}

Construction cost was around ₹ 1.73 lakh. Major five beneficiary farmers were contacted to assess the impacts of the structure. Average water rise was found to be about $25 \mathrm{ft}$. Total area of cultivation was increased from 13 to 16 acre. Total income rise was investigated around 1.2 lakh rupees.

\section{Structure-4}

Construction cost of this structure was around ₹ 4.93 lakh. Major five beneficiary farmers were contacted to assess the impacts of the structure. Average water rise was found to be about $23 \mathrm{ft}$. Total area of cultivation was increased from 25 to 28 acre. Total income rise was investigated around 1.1 lakh rupees.

\section{Structure-5}

Construction cost of this structure was around ₹ 2.98 lakh. Major five recipient farmers were reached to survey the effects of the structure. Normal water rise was found to be about $35 \mathrm{ft}$. Total area of cultivation was expanded from 69 to 79 acre. Total income rise was investigated around 2.6 lakh rupees.

\section{Structure-6}

Development cost for this structure was around ₹ 6.75 lakh. Major five beneficiary farmers were reached to survey the effects of the structure. Average water rise was found to be about $40 \mathrm{ft}$. Total area of cultivation was expanded from 12 to 15 acre. Total income rise was observed around one lakh rupees.

\section{Structure-7}

Building cost for this structure was around ₹ 5.39 lakh. Significant five beneficiary farmers were reached to survey the effects of the structure. Average water rise was found to be about $33 \mathrm{ft}$. Total area of cultivation was extended from 51 to 62 acre. Total income rise was seen around 3.6 lakh rupees.

\section{Structure-8}

Construction cost for this structure was around ₹ 5.08 lakh. Major four beneficiary farmers were contacted to survey the impacts of the structure. Average water rise was found to be about $30 \mathrm{ft}$. Total area of cultivation was extended from 16 to 20 acre. Total income rise was investigated around 1.2 lakh rupees.

\section{Structure-9}

Cost of construction for this structure was around ₹ 1.71 lakh. Major six beneficiary farmers were communicated to survey the effects of the structure. Average water rise 
was found to be about $25 \mathrm{ft}$. Total area of cultivation was extended from 23 to 26 acre. Total income rise was investigated around 0.7 lakh rupees.

\section{Influence of structures on area of farming}

The data was collected from the farm owners near these structures. After construction of these IWMP-2 structures, in all of the influenced farms, the area under cultivation was increased which can be observed in Table 2 and Figure 2. Structure numbers 1, 5 and 7 have increased the area of farming drastically in nearby farms. As the structure holds water in stream, it increases water levels as well. As the tribal area, most of the farmers depend on rainfed agriculture. Due to structures, many of small farmers were able to grow in more area as water availability increased. Combining all structures, total area under cultivation increased around 62 acre which directly improves farmers' income.

\section{Influence of structures on crop pattern and its production}

Crop pattern was observed to be changed after the structures were constructed which is visible in Table 3 and Figure 3. As Availability of water was increased, better value crops were chosen from farmers.
Farmers started to choose potato crop over wheat as it gives more production.

In summer, onion's cultivation was found to be increased remarkably as it gave higher prices. Potato and onion cultivation area was increased about 40 and 22 acre respectively in total. The cultivation of some other vegetable crops such as cabbage, coriander, etc. was also increased after the structures constructed. Area of crops grown in summer was found to be increased radically as compared to crops in monsoon season.

As an effect of increased crop cultivation, the production of potato and onion was seen to be increased about 960 and 1155 quintals per year which was high beneficiary impact on farmers as can be seen from Figure 4.

\section{Benefit-cost analysis}

The analysis shows that in five years period, considering the agriculture benefits only; cost of all the structures was recovered except structure-6. Table 4 shows that structure number 1 and 4 were having BCR more than one in 5 years period. Structure number 2, 3, 5 and 7 were having BCR above 3 and structure number 9 was having BCR above 2, which shows that the structures were able to recover the cost more than three times just in period of five years.

Table.1 Data collection from farmers

\begin{tabular}{|c|c|}
\hline Sr. No. & Data collected \\
\hline $\mathbf{1}$ & Structure type \\
\hline $\mathbf{2}$ & Cost of construction \\
\hline $\mathbf{3}$ & Water table difference \\
\hline $\mathbf{4}$ & Major beneficiaries farmers \\
\hline $\mathbf{5}$ & Area under cultivation \\
\hline $\mathbf{6}$ & Crop pattern \\
\hline $\mathbf{7}$ & Crop Production \\
\hline $\mathbf{8}$ & Local market price \\
\hline
\end{tabular}


Table.2 Influence of structures on area of cultivation

\begin{tabular}{|c|c|c|c|c|}
\hline No. of Structures & Year of construction & Name of village & \multicolumn{2}{|c|}{ Area under cultivation (acre) } \\
\cline { 3 - 5 } & & & Before & After \\
\hline $\mathbf{1}$ & 2013 & Malendi & 59.3 & 74.4 \\
\hline $\mathbf{2}$ & 2013 & Badgonda & 118.0 & 123.2 \\
\hline $\mathbf{3}$ & 2012 & Badiya & 12.7 & 15.8 \\
\hline $\mathbf{4}$ & 2013 & Badgonda & 25.3 & 29.7 \\
\hline $\mathbf{5}$ & 2013 & Badgonda & 68.6 & 78.5 \\
\hline $\mathbf{6}$ & 2013 & Malendi & 11.1 & 15.4 \\
\hline $\mathbf{7}$ & 2013 & Badgonda & 50.7 & 61.5 \\
\hline $\mathbf{8}$ & 2014 & Badgonda & 16.1 & 20.7 \\
\hline $\mathbf{9}$ & 2012 & Badiya & 24.1 & 28.4 \\
\hline & Total & & 385.8 & 447.6 \\
\hline
\end{tabular}

Table.3 Influence of structures on crop pattern and production

\begin{tabular}{|c|c|c|c|c|c|}
\hline \multirow{2}{*}{ Sr. No. } & \multirow{2}{*}{ Crop } & \multicolumn{2}{|c|}{ Area (acre) } & \multicolumn{2}{c|}{ Production (quintal) } \\
\cline { 3 - 6 } & & Before & After & Before & After \\
\hline $\mathbf{1}$ & Soybean & 191.5 & 194.9 & 1192 & 1256 \\
\hline $\mathbf{2}$ & Potato & 55.8 & 96.4 & 1380 & 2340 \\
\hline $\mathbf{3}$ & Onion & 23.2 & 45.7 & 1125 & 2280 \\
\hline $\mathbf{4}$ & Wheat & 106.1 & 95.5 & 1521 & 1269 \\
\hline $\mathbf{5}$ & Cabbage & 3.7 & 6.2 & 6 & 60 \\
\hline $\mathbf{6}$ & Coriander & 3.1 & 4.6 & 10 & 11 \\
\hline $\mathbf{7}$ & Okra & 0.9 & 2.2 & 19.5 & 45.5 \\
\hline $\mathbf{8}$ & Sponge gourd & 1.5 & 2.2 & 25 & 35 \\
\hline & Total & 385.8 & 447.6 & 5278.5 & 7296.5 \\
\hline
\end{tabular}

Table.4 Benefit-cost analysis of structures

\begin{tabular}{|c|c|c|c|c|c|}
\hline $\begin{array}{c}\text { Structure } \\
\text { number }\end{array}$ & $\begin{array}{c}\text { Name of } \\
\text { village }\end{array}$ & $\begin{array}{c}\text { Cost of } \\
\text { construction } \\
(\mathbf{F})\end{array}$ & $\begin{array}{c}\text { One year profit from } \\
\text { agriculture }\end{array}$ & $\begin{array}{c}\text { Profit in } \\
\text { five years }\end{array}$ & $\begin{array}{c}\text { Benefit- } \\
\text { cost ratio }\end{array}$ \\
\hline $\mathbf{1}$ & Malendi & 1081000 & 243000 & 1215000 & 1.1 \\
\hline $\mathbf{2}$ & Badgonda & 331000 & 239700 & 1198500 & 3.6 \\
\hline $\mathbf{3}$ & Badiya & 173000 & 116550 & 582750 & 3.4 \\
\hline $\mathbf{4}$ & Badgonda & 493000 & 111000 & 555000 & 1.1 \\
\hline $\mathbf{5}$ & Badgonda & 298000 & 204400 & 1022000 & 3.4 \\
\hline $\mathbf{6}$ & Malendi & 675000 & 101100 & 505500 & 0.7 \\
\hline $\mathbf{7}$ & Badgonda & 539000 & 360650 & 1803250 & 3.3 \\
\hline $\mathbf{8}$ & Badgonda & 508000 & 117700 & 588500 & 1.2 \\
\hline $\mathbf{9}$ & Badiya & 171000 & 93200 & 466000 & 2.7 \\
\hline
\end{tabular}


Fig.1 Location map of the study area

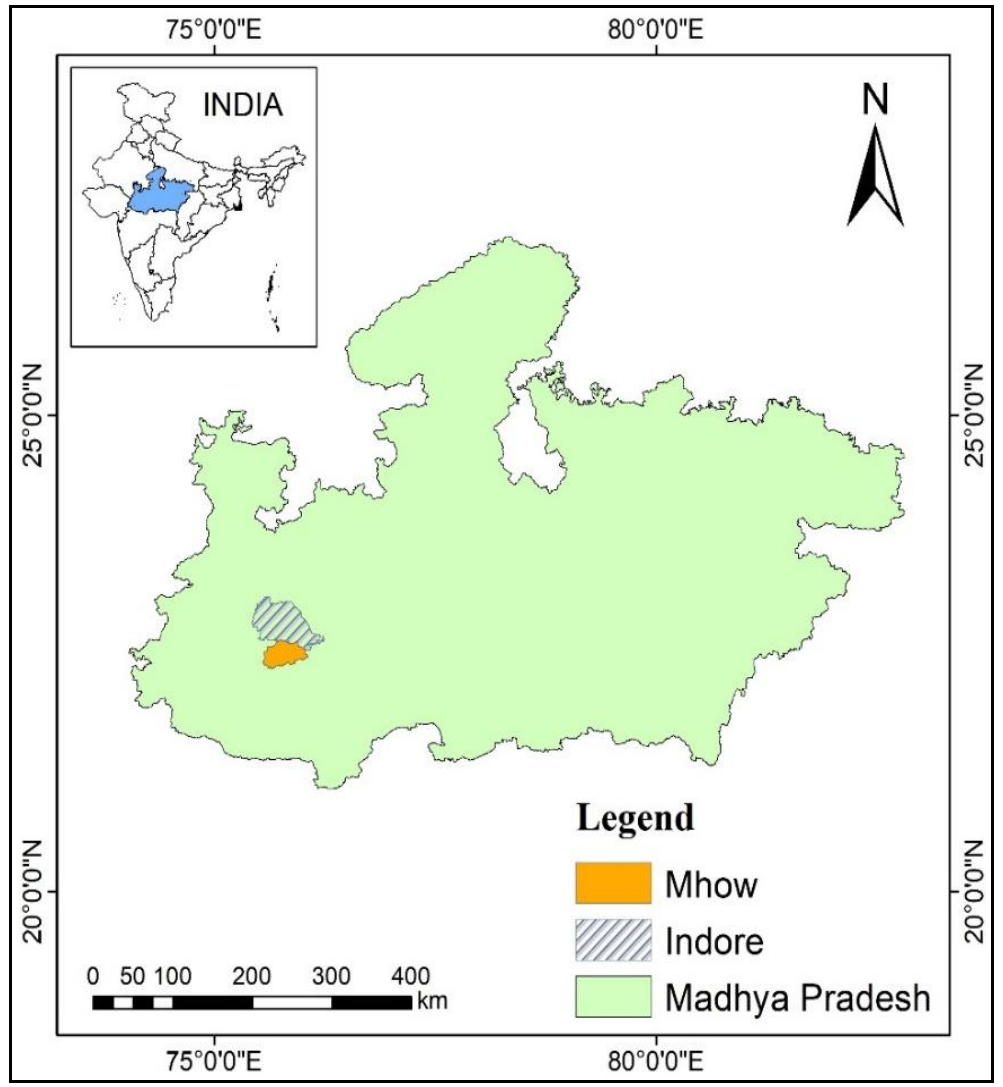

Fig.2 Impact of structures on area of cultivation

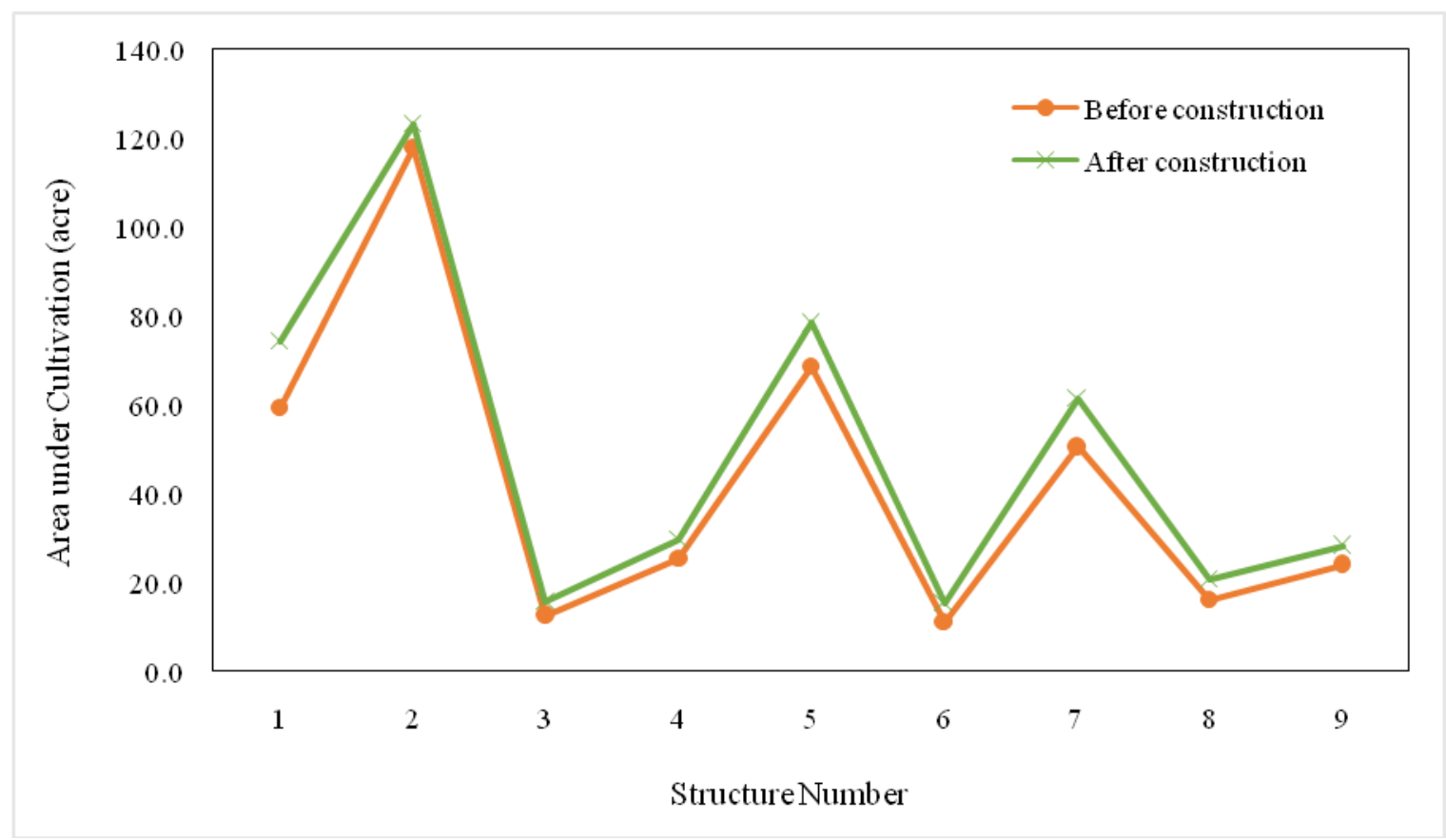


Fig.3 Impact of structures on different crop area

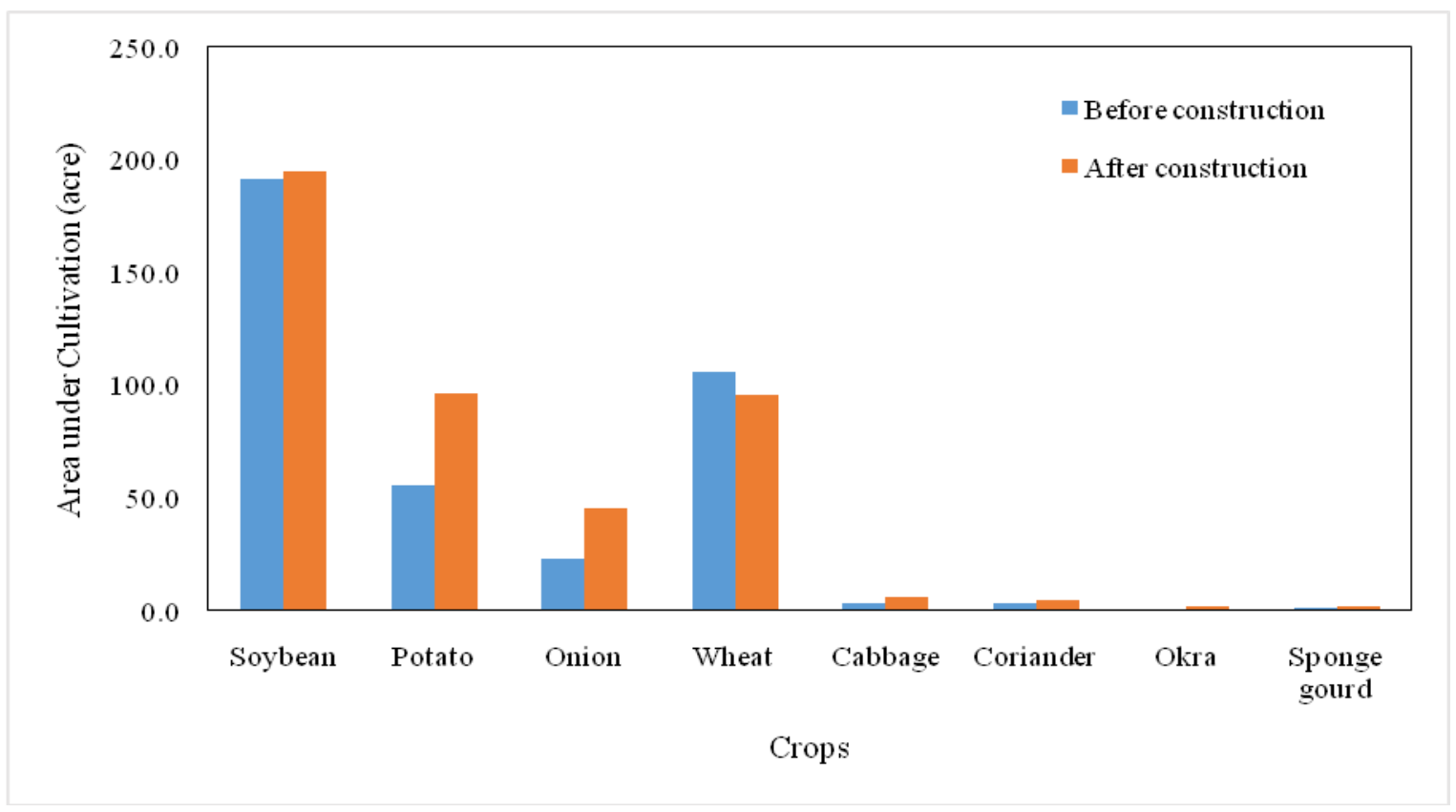

Fig.4 Impact of structures on different crop production

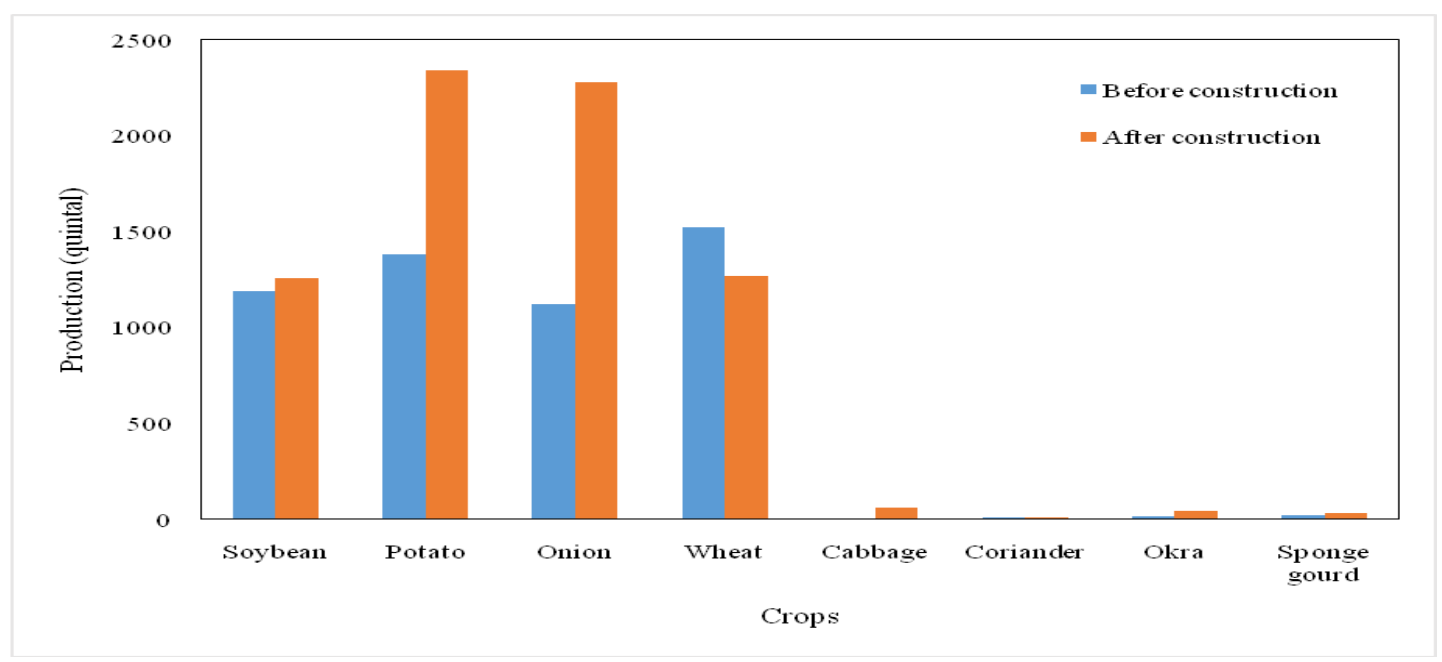

The place where structure is being built influences a lot on recovery and benefits due to same. As it can be clearly seen that structure-2 was built for cost of 3.3 lakh rupees and already recovered 11 lakhs in five years, which shows efficiently placed built of conservation structure which conserves more soil and water and don't submerge farmers' lands. On contrary to that structure 6 was built for relatively expensive 6.75 lakh rupees and could only recover around 5 lakh in five years which may be due to its poor location that doesn't retain as much water. Total cost of all these 9 structures in IWMP-2, Mhow, Indore was around 43 lakhs INR and they combine were able to recover around 79 lakh INR in just five years. Overall, almost all the structures were found to be very valuable for 
the farmers nearby and contributed a lot in profiting them.

Discussion of the study is as follows:

Initiative to encourage villagers for vermicomposting in tribal area of Mhow led to significant produce of natural fertilizer which eventually benefited people in saving their costs of fertilizers.

Under IWMP, farmers were provided with better quality seeds of various crops which improved their productivity.

Structures constructed under IWMP, reduced the erosion and stored more water which led to increase in ground water level during winter and summer season as well.

Due to structures' influence, beneficiary farmers were able to cultivate more land and better gaining crops during summer season which directly increased their income considerably.

Small farmers who largely relied on rainfall and natural streams for irrigation, were majorly benefited due to IWMP compared to medium farmers.

From benefit cost analysis of nine structures, it came out that all the cost of construction of structures was easily recovered in just two to three years period which would continue to benefit tribal farmers nearby for more years.

\section{Acknowledgments}

We are sincerely thankful to Development Support Centre (DSC) teams including $\mathrm{Mr}$. SachinOza, Executive Director and $\mathrm{Mr}$. Mohan Sharma, Program Director for providing us this opportunity to engage this study and to provide necessary information and support as well.

\section{References}

Chandramauli, C. 2011. Provisional Population Totals Paper 1 of 2011 India Series 1. In: Census of India 2011; Office of the Registrar General \& Census Commissioner: New Delhi, India; Chapter 6.

Dixon, J. A. and Easter, K. 1986. Integrated Watershed Management - An Approach to Watershed Resource Management; Westview Press: Boulder, CO, USA.

Fledderjohann, J., Doyle, P., Campbell, O., Ebrahim, S., Basu, S. and Stuckler, D. 2015. What do Indian children drink when they do not receive water? Statistical analysis of water and alternative beverage consumption from the 2005-2006 Indian National Family Health Survey. BMC public health, 15(1): 612.

Nerkar, S. S., Tamhankar, A. J., Johansson, E. and Lundborg, C. S. 2016. Impact of Integrated Watershed Management on Complex Interlinked Factors Influencing Health: Perceptions of Professional Stakeholders in a Hilly Tribal Area of India. International journal of environmental research and public health, 13(3): 285.

Newkirk R.T. 1999. Cost-benefit analysis. In: Environmental Geology. Encyclopedia of Earth Science. Springer, Dordrecht.

Singh, P., Behera, H. C. and Singh, A. 2010. Impact and effectiveness of "watershed development programmes' in India. Mussorrie India Centre Rural Stud, 29: 1-55.

\section{How to cite this article:}

Gojiya, K.M., C.S. Matholiya and Gaadhe, S.K. 2018. Impact Analysis of Integrated Watershed Management Program on Farmers' Income in a Hilly Tribal Area of India. Int.J.Curr.Microbiol.App.Sci. 7(12): 2521-2529. doi: https://doi.org/10.20546/ijcmas.2018.712.286 